Studies of twins show that the concordance rate for manic-depressive disorder is $80 \%$ in monozygotic twins compared with $8 \%$ in dizygotic twins. Together with adoption studies, these findings suggest that genetic factors are involved in the familial transmission of bipolar disorder. Although less compelling, the results of twin and adoption studies suggest that genetic factors are also involved in major depression. In Mood Genes, Barondes lucidly encompasses the development of modern psychiatry and genetics, and shows how the two are coupled in the quest for the genetic basis of mood disorders.

He starts with the story of Michael, a molecular biologist whose mother, Flora, is a writer with severe manic-depressive illness; she has bouts of profligate spending and sexual promiscuity followed by crashes into hopeless depression. When manic, she writes for at least 15 hours a day, producing 300 typed pages in just three weeks. Flora considers mania to be her "gemlike flame," reminiscent of the madness that drove many creative minds, as essayed by Kay Redfield Jamison in Touched with Fire (Simon and Schuster, 1993), which is a perfect complement to Mood Genes. Flora's brother, who is depressive and who has attempted suicide on several occasions, her father and Michael's son also exhibit signs consistent with manicdepressive illness. In his fifties, Michael feels down and takes the antidepressant Prozac, which throws him too into mania. It is on this family, affected by manic-depressive disorder in four successive generations, that Barondes builds the riveting story of psychiatry and genetics.

He explains how Emil Kraepelin tried to classify psychiatric disorders, as Rudolph Virchow had done for medical diseases. Kraepelin concluded from pedigree studies that manic-depressive insanity was a hereditary trait. To pursue this proposition he established in 1917 a Genealogical and Demographic Department in the Kaiser Wilhelm Institute for Psychiatry in Munich. But his work was undone by Ernst Rudin, appointed head of the department by Kraepelin, who was instrumental during the early Nazi era in drafting the infamous Law to Prevent Hereditarily Sick Offspring, which led to the compulsory sterilization of hundreds of thousands of people with real or constructed hereditary or congenital disease.

This tarnished Kraepelin's reputation and brought to an abrupt halt the development of psychiatric genetics, opening the way for Sigmund Freud's more compassionate, but arguably less rational, psychoanalytical approach to become the predominant force in psychiatry. The renaissance of interest in the classification of psychiatric disorders did not occur until the 1970s, forced in part by the development of powerful psychotropic drugs including lithium, the most effective drug for controlling manic symp- toms. Preparation for the gene hunt is completed by the familiar account of the development of human genetics, from the peas of Gregor Mendel to the double helix and the genetic code.

The important concept of gene penetrance is introduced by reference to the genetically transmitted illness porphyria, which allegedly affected King George III and is expressed in only about one in ten carriers of the disease allele under conditions of 'biochemical overload'. Porphyria has heuristic value for understanding the genetic transmission of complex diseases, such as high blood pressure, diabetes and manic depression, in which factors extrinsic to the genome trigger the expression of the disease allele. This seems to have been the case for Michael, as he devel-

oped mania only after taking Prozac.

Barondes dismisses rather peremptorily the candidate gene approach (looking for genes that appear biologically relevant to the disorder) in the hunt for mood genes. Although it has found genes involved in other diseases, he says it has failed to find mood genes. But many studies are now in progress, and three recent reports link a polymorphism in the gene encoding the serotonin transporter, the target for Prozac, with mood disorders. Barondes instead focuses on the linkage approach, beginning his explanation with the studies of Thomas Morgan on the fruitfly, and underscoring the importance of restriction fragment length polymorphisms as gene markers.

James Gusella and Michael Conneally

\title{
Higher planes
}

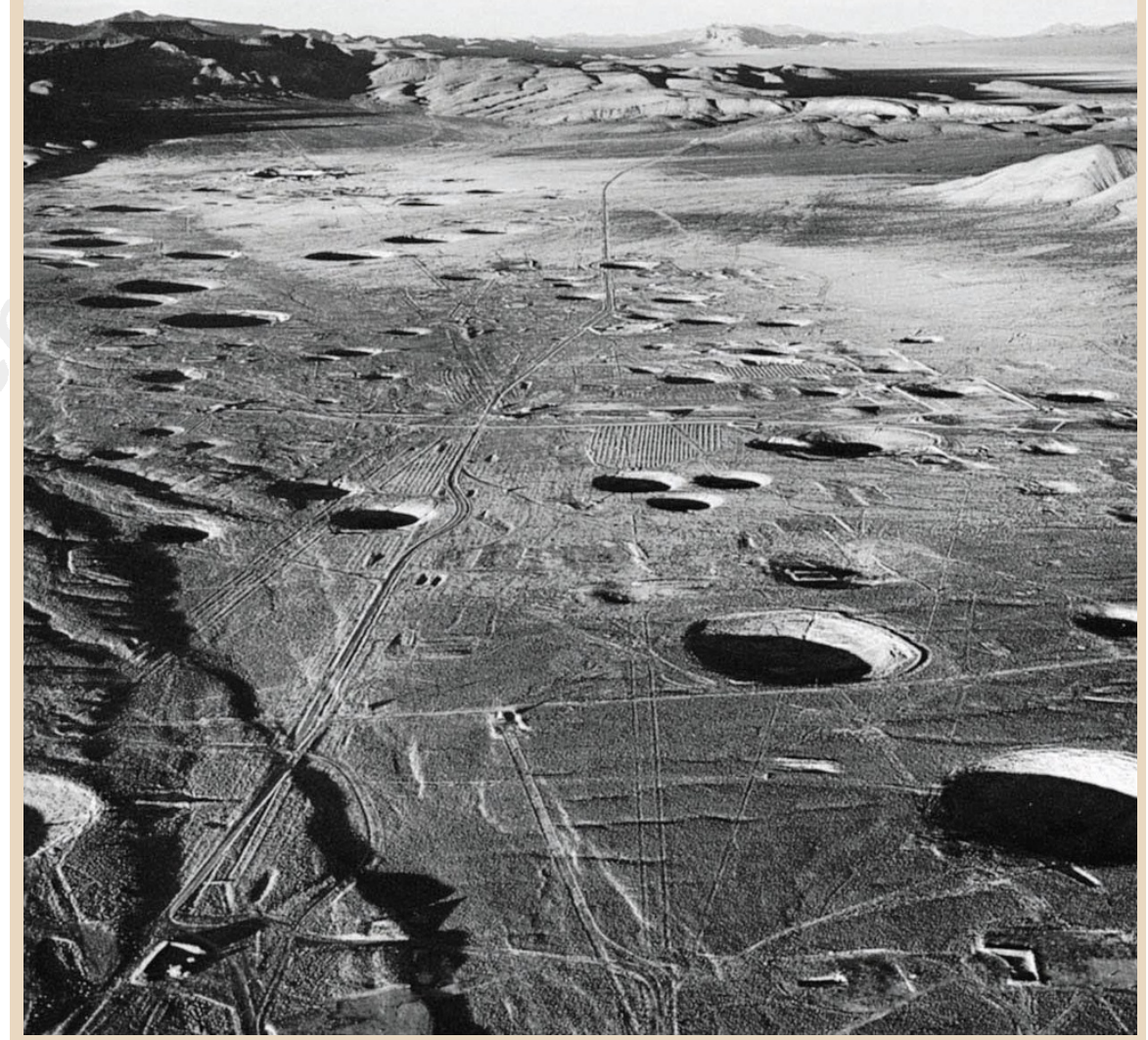

In the words of internationally renowned photographer Emmet Gowin, the landscape "is always, in some sense, our home". For the past ten years, Gowin has used aerial photography to document man's mark on the Earth in images of industrial agriculture, mining explorations and nuclear test sites of the American West. In some sense, the aerial perspective provides the gift of seeing our own history, although known to us, for the first time. The exceptional beauty of the photographs is sometimes at odds with what they depict, and we are gently reminded that we are connected to, not separate from, these places. Gowin wishes simply to bear witness to this reality, and his work is full of reverence for life. With the recent tragic halt to nuclear nonproliferation in Asia, let us hope that this philosophy finds global expression.

This photograph, "Subsidence Craters and the Yucca Fault, Northern End of Yucca Flat, Nevada Test Site", is part of an exhibition of Gowin's work taking place at the Pace Wildenstein MacGill Gallery in New York City until 13 June. A book of 250 of Gowin's photographs is planned.

Lisa Satterwhite is in the Department of Molecular Biology, Schultz Laboratory, Princeton University, Princeton, NJ 08544, USA. 